\title{
Application of Titanium and its Alloys for Automobile Parts
}

\author{
Kazuhiro Takahashi ${ }^{a,{ }^{*}}$, Kenichi Mori ${ }^{\text {a }}$, Hidenori Takebe ${ }^{\text {a }}$ \\ ${ }^{a}$ Steel Research Laboratories, Nippon Steel Corporation, Chiba,Japan \\ *takahashi.2xa.kazuhiro@jp.nipponsteel.com
}

\begin{abstract}
Titanium and its alloys have been applied to motorcycles and automobiles in order to reduce the weight of their component parts. In recent years, titanium exhaust systems, engine valves and connecting rods have been widely applied mainly to sports type or large motorcycles. In addition to Ti-6Al-4V, Ti-Al-Fe alloys which utilize Fe as an inexpensive and a common alloying element are used for engine valves and connecting rods. In exhaust systems, such as mufflers, at first, Gr.2 commercially pure titanium sheets have been mainly used because of their high cold formability. Furthermore, several titanium alloys to which $\mathrm{Cu}, \mathrm{Al}, \mathrm{Si}$ and $\mathrm{Nb}$ are added have been actively developed in order to improve strength, creep properties, oxidation resistance and so on at elevated temperatures, as service temperature becomes higher. Also, due to the development of processing technologies, the same methods and processes that are used for manufacturing steel parts have been applied to titanium ones, and the application of titanium has recently been expanded to fracture-split connecting rods and fuel tanks. Newly, titanium foil has been adopted as a separator of PEFC used in fuel cell vehicles from the viewpoints of excellent corrosion resistance and cold formability. As mentioned above, in this presentation, the technical contents of titanium products and parts developed for motorcycles and automobiles are reviewed.
\end{abstract}

\section{Introduction}

The ratio of material composition of general cars, super sports motorcycles and large commercial aircraft is shown in Figure 1. In terms of aircraft and high-end motorcycles, multi-materialization has been progressed, and for example, Boeing B787 and Airbus A 350 aircrafts are roughly composed of 50\% of composite materials, $20 \%$ of aluminum, 15\% of titanium, and $10 \%$ of steel in mass ratio, respectively. The rate of application of composites has been increased by three to five times compared to that of the previous generation of aircrafts [1]. Due to the increase in the ratio of composite materials, the ratio of titanium has been increased from the viewpoint of high specific strength, different material contact corrosion, and thermal expansion difference. For a $1000 \mathrm{cc}$ super sports motorcycle, the mass ratio is roughly $40 \%$ of steel, $35 \%$ of aluminum, $10 \%$ of resin, $8 \%$ of other metals (titanium, magnesium), to which aluminum and other metals (titanium, magnesium) are applied more than to $125 \mathrm{cc}$ commuters and the total amount of these metals exceeds that of steel [2] [3]. The weight of aircrafts together with that of high-end motorcycles has been reduced; however, the former has been resulted from improving fuel efficiency, while the latter has been due to improvement of travelling performance (engine performance, maneuverability, etc.). On the other hand, in four-wheeled vehicles, the amount of steel used is overwhelmingly large, in which the composition ratio is $70 \%$ of steel, $10 \%$ of non-ferrous metals mainly containing aluminum, and $10 \%$ of resin. High tensile strength steel has already been applied for reducing the weight. In the future, it is expected that multi-materialization using aluminum and resin will be advanced [4]. As shown in Table 1, automobiles (cars), super sports motorcycles, and large commercial aircrafts are listed in ascending order of mass price, which is considered to be corresponding to the current advancement of multi-materialization. 
Since the density of titanium is less than $60 \%$ of that of steel, the specific strength of commercially pure titanium sheets with tensile strength of $440 \mathrm{MPa}$ and $30 \%$ elongation corresponds to that of steel sheets with tensile strength of $780 \mathrm{MPa}$. Also, the specific strength of titanium alloy sheets with tensile strength of 780MPa is almost equivalent to that of steel sheets with tensile strength of $1.4 \mathrm{GPa}$. Furthermore, since the tensile strength of Ti-6Al-4V that is generally used for aircrafts and the like is 900 to $1000 \mathrm{MPa}$, it corresponds to the 1.6 to $1.7 \mathrm{GPa}$ class of steel, which has a remarkable potential. In terms of specific rigidity as a structural material, in the case of bending rigidity, density is dominant and the specific strength-specific rigidity balance of titanium among metal materials is never inferior. Since the strength of some aluminum alloys and magnesium alloys reduces significantly at temperatures of 100 to $200^{\circ} \mathrm{C}$ or higher, it can be said that titanium alloys are more advantageous.

In order for such excellent properties of titanium to be fully exhibited in the automotive field, various efforts and technological developments for reducing the production cost of parts have been made by automobile and parts manufacturers and material producers. For example, existing processing manufacturers and material producers have cooperated to select press forming conditions in consideration of the in-plane anisotropy and lubricity of commercially pure titanium sheets, and manufacture titanium parts by utilizing the plants and equipment used for manufacturing steel parts, such as press, forging, and welding equipment. In the following chapter, the application technology of titanium and titanium alloy in recent years for fuel tanks, connecting rods, engine valves, exhaust system and fuel cell separators will be introduced.

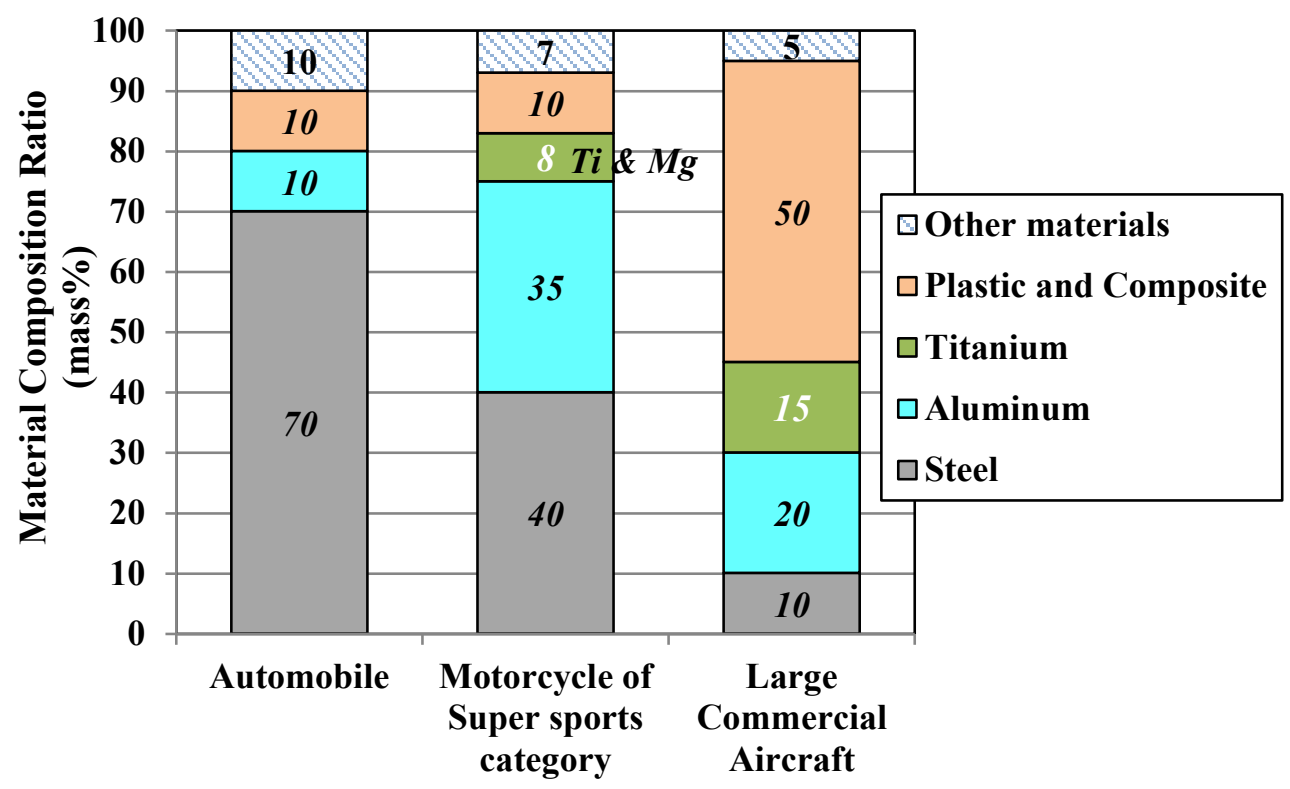

Figure 1. Material composition ratio in mass of automobile, super sports motorcycle and large commercial aircraft

Table 1. Approximate price per unit mass of automobile, super sports motorcycle and large commercial aircraft

\begin{tabular}{cr} 
Vehicle & \multicolumn{2}{c}{ Approximate Price } \\
& per unit mass $(\$ / \mathbf{k g})$ \\
\hline Automobile & 20 \\
Motorcycle of Super sports category & 100 \\
Large Comme rcial Aircraft & 1,000 \\
\hline
\end{tabular}




\section{Titanium Applications for for Automobile Parts}

Fuel tank

Fuel tanks are the part to which titanium has been most recently adopted for commercial motorcycles. Figure 2 shows the appearance of the fuel tanks made of commercially pure titanium sheet, JIS class1, in motorcycles released from HONDA in 2017 and 2018. The weight reduction of the fuel tank is an important issue for two-wheeled vehicles because it leads to the stabilization of maneuverability by lowering the center of gravity as well as improving the fuel consumption [5]. In recent years, lightweight materials have come to be adopted instead of surface-treated steel sheets. Figure 3 shows the appearance of the fuel tanks made of (a) resin multilayer and (b) commercially pure titanium sheet JIS class 1 . A resin mainly made of high density polyethylene (HDPE) has a density of approximately $0.95 \mathrm{~g} / \mathrm{cm}^{3}$ which is considerably lower than that of titanium and is already widely used as fuel tank material. On the other hand, EURO5, which will be implemented in 2020, is expected to tighten fuel gas permeation regulations. In order to satisfy the regulation of fuel permeation, it is necessary to form fuel tanks with resin multilayer structure including ethylene vinyl alcohol copolymer resin (EVOH) or polyamide as a barrier layer [6]. As a result, the total thickness of the resin-layers needs to be approximately 6 to $7 \mathrm{~mm}$. If fuel tanks of the same volume as that of such a resin multilayer structures are designed with titanium sheets, it is estimated that $0.7 \mathrm{~mm}$ in wall thickness is sufficient and that the weight of the fuel tank becomes approximately $40 \%$ lighter than that of resin multilayer structure.

As a lightweight material other than resin, aluminum alloys such as 5000 series having density of approximately $2.65 \mathrm{~g} / \mathrm{cm}^{3}$ are used. In general, however, aluminum alloys have low ductility and a small Lankford value ( $\mathrm{r}$ value), which show considerably poor press-formability. Furthermore, because the heat conductivity of aluminum is high, the heat input for welding cannot easily be concentrated, and burn-through of butt-weld tends to occur when the welding equipment for steel is used. In addition, it is necessary to apply high electrode pressure even in spot welding. From these problems, it is considered that an increase in the wall thickness is inevitable when manufacturing aluminum alloy fuel tanks with ordinary equipment for steel fuel tanks. On the other hand, a special welding method has been developed for aluminum alloys and the fuel tanks made of aluminum alloy have been manufactured [7].

In contrast, commercially pure titanium sheets are known to have excellent deep drawability. Figure 4 shows the relationship between r-value and limiting drawing ratio of various metals. Since the ratio of drawing limit monotonously increases with an increase in $r$ value, JIS Class1 commercially pure titanium (TP270C) that has higher $r$ value than aluminum alloys shows the higher ratio of drawing limit than aluminum alloys. Although it is known that the stretchability of titanium is not considerably high in general, TP270C that has been applied to fuel tanks has stretchability comparable to that of low carbon steel usually used for press forming processes. Due to its similar strength to that of steel sheets for fuel tanks, TP270C is considered to be the most appropriate material for fuel tanks of mass-produced motorcycles. However, in-plane anisotropy of titanium sheets and lubrication during press forming are taken into consideration as issues in press forming titanium cold rolled sheets. In addition, seam welding and spot welding, which are commonly carried out in manufacturing fuel tanks of motorcycles, are resistance welding performed in a short time and they can easily be conducted on TP270C sheets even in the atmosphere of air. Spot welding of titanium is possible under the same conditions as that of steel, except for the appropriate welding currents of titanium that are slightly different from those of steel sheets [8]. As described above, titanium fuel tanks can be manufactured by utilizing the 
manufacturing lines used for press forming steel sheets and welding them.
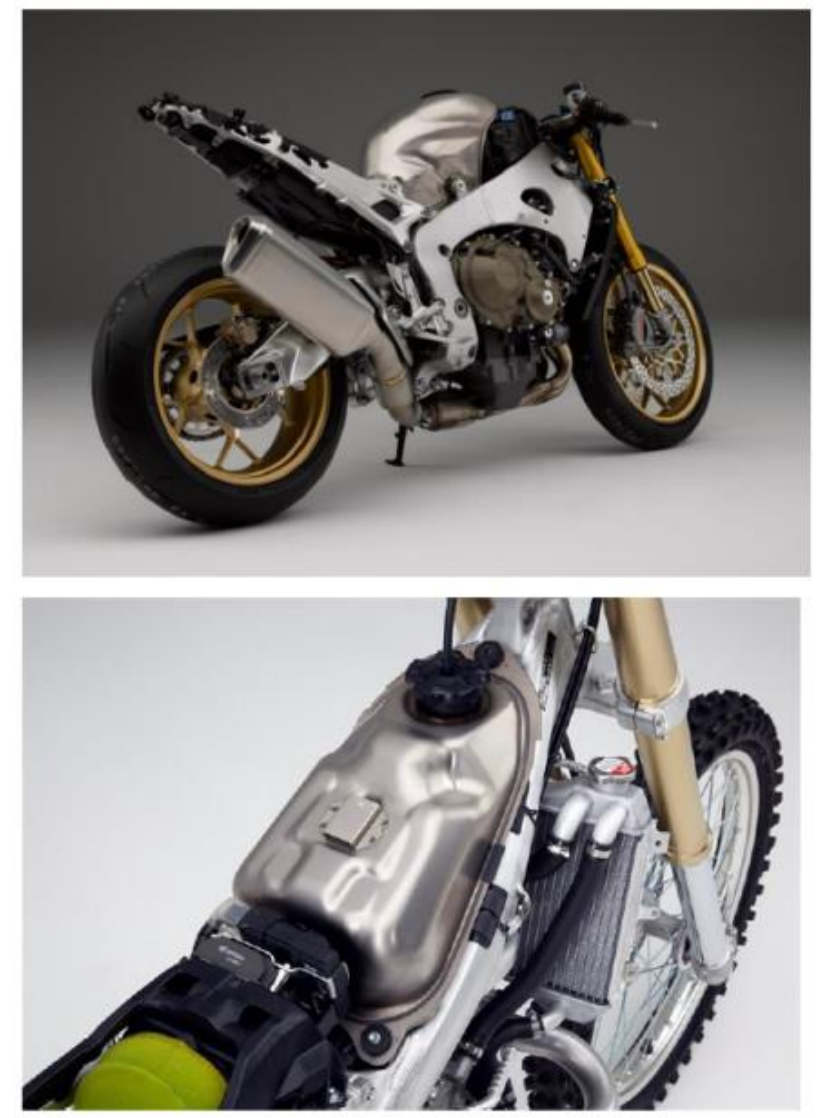

Figure 2. Appearance of a fuel tank made of JIS Class 1 commercially pure titanium sheet

Upper : HONDA CBR1000RR SP, 2018, Lower : HONDA CRF450R, 2017

(Courtesy of Honda Motor Corporation)

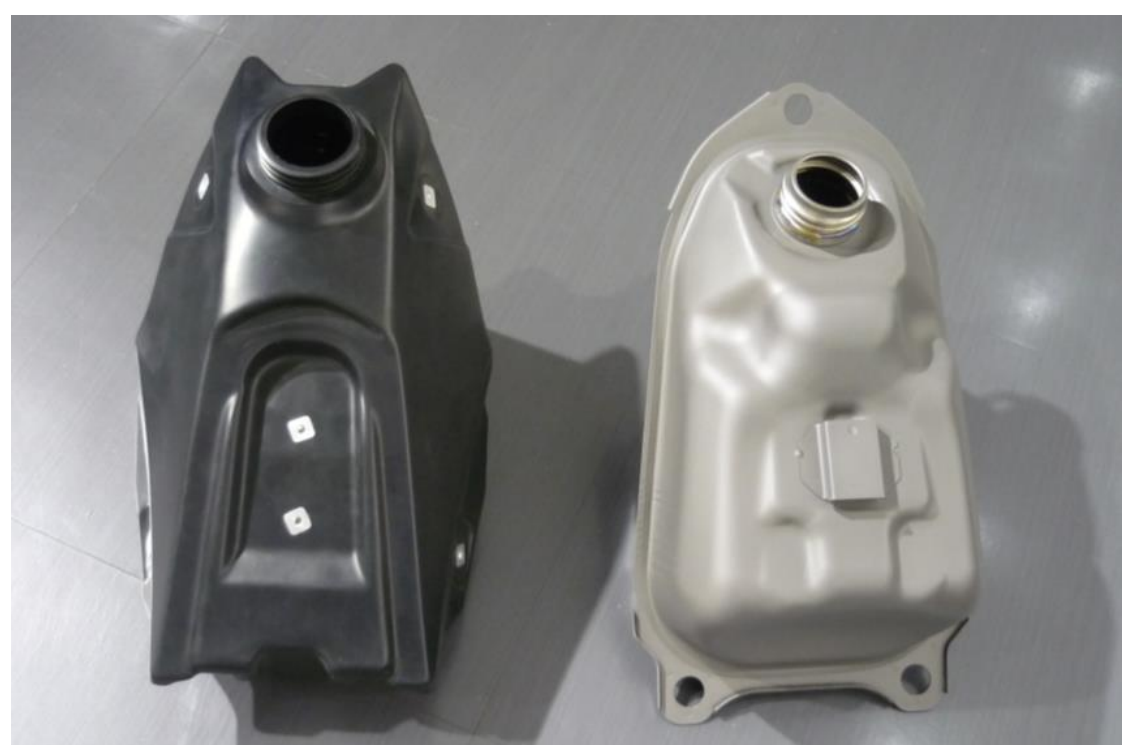

$\begin{array}{ll}\text { (a) Resin multilayer } & \text { (b) Commercially pure titanium sheet }\end{array}$

Figure 3. Appearance of the fuel tanks made of (a) Resin multilayer and (b) commercially pure titanium sheet JIS class1. 


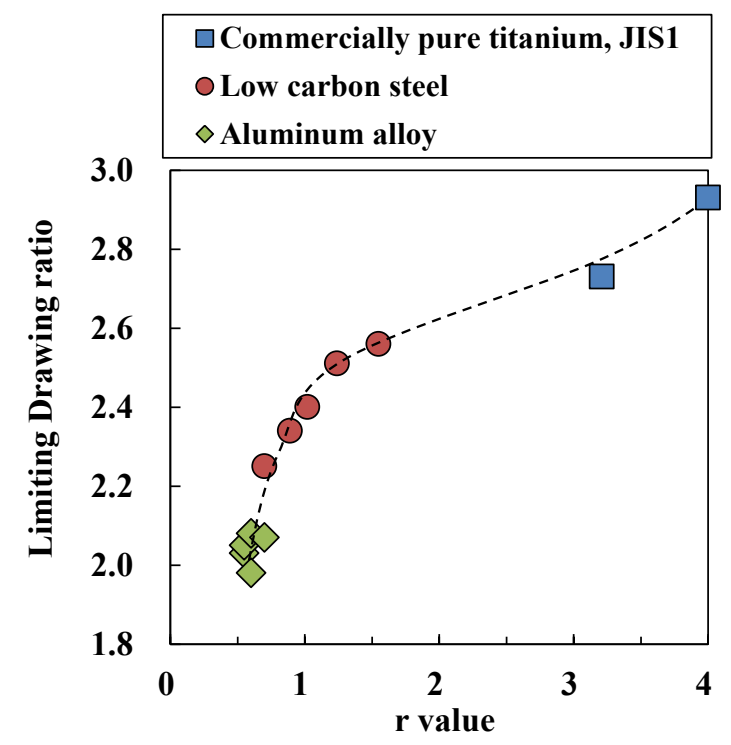

Figure 4. Relationship between $r$ value and limiting drawing ratio

of commercially pure titaniums, low carbon steels and aluminum alloys.

\section{Connecting rods}

Reducing the weight of connecting rods makes it possible to improve the driving response and to increase the rotation speed of engines. In particular, high specific fatigue strength (fatigue strength / mass) is required for connecting rods of motorcycles because the rotation speed of engines is considerably high in motorcycles [9]. The connecting rods of motorcycles are usually exposed at temperatures under $300^{\circ} \mathrm{C}$. Therefore, the study to apply titanium alloys for connecting rods got started decades ago, and it was in 1987 that Ti-6Al-4V was first adopted for a motorcycle[10],[11], and Ti-3Al-2.5V-REM-S was adopted for HONDA NSX, mass-produced-four-wheeled-vehicle [12], [13]. In 2014, Ti-5Al-1Fe [14],[15],[16],[17], which does not contain V, was adopted for YAMAHA YZF-R1, achieving a weight reduction of approximately $20 \%$ compared to steel [9]. It is noteworthy that the fracture split (FS) method on the large end of connecting rods, which is mainly used for steel currently, was applied for titanium alloy for the first time. Figure 5 shows an appearance of the fracture split connecting rods made of Ti-5Al-1Fe of YAMAHA YZF-R1.

In addition to manufacturing connecting rods, reductions in processing costs such as hot forging, cutting and polishing are also required. For example, Ti-5 Al-1Fe has a hot deformation stress that is equivalent to or slightly higher than that of low alloyed steel, SCM420, which is lower by 15 to $20 \%$ than that of Ti-6Al-4V [9]. Furthermore, the drill machinability (maximum cutting speed at which a certain cutting hole length can be continuously machined) of Ti-5Al-1Fe is also improved by approximately $15 \%$ compared to Ti-6Al-4V. Since titanium alloys show lower thermal conductivity by $30 \%$ or less than steel, sliding heat tends to be built up and titanium alloys easily react with other metals to cause severe adhesion wear. Therefore, it is necessary to find some means for securing resistance against adhesion and wear at the sliding portion of titanium alloy connecting rods at the lowest cost. As for the surface coating of the connecting rods of YAMAHA YZF-R1, CrN was adopted from the evaluation results of $\mathrm{CrN}$, NiP and TiAlN [9]. The Young's modulus of titanium alloys is approximately a half of that of steel. In order to obtain the same rigidity as that of steel, the shape of connecting rods is designed in which the thickness is partially increased. Increasing the Young's modulus is an issue that is required for materials. 

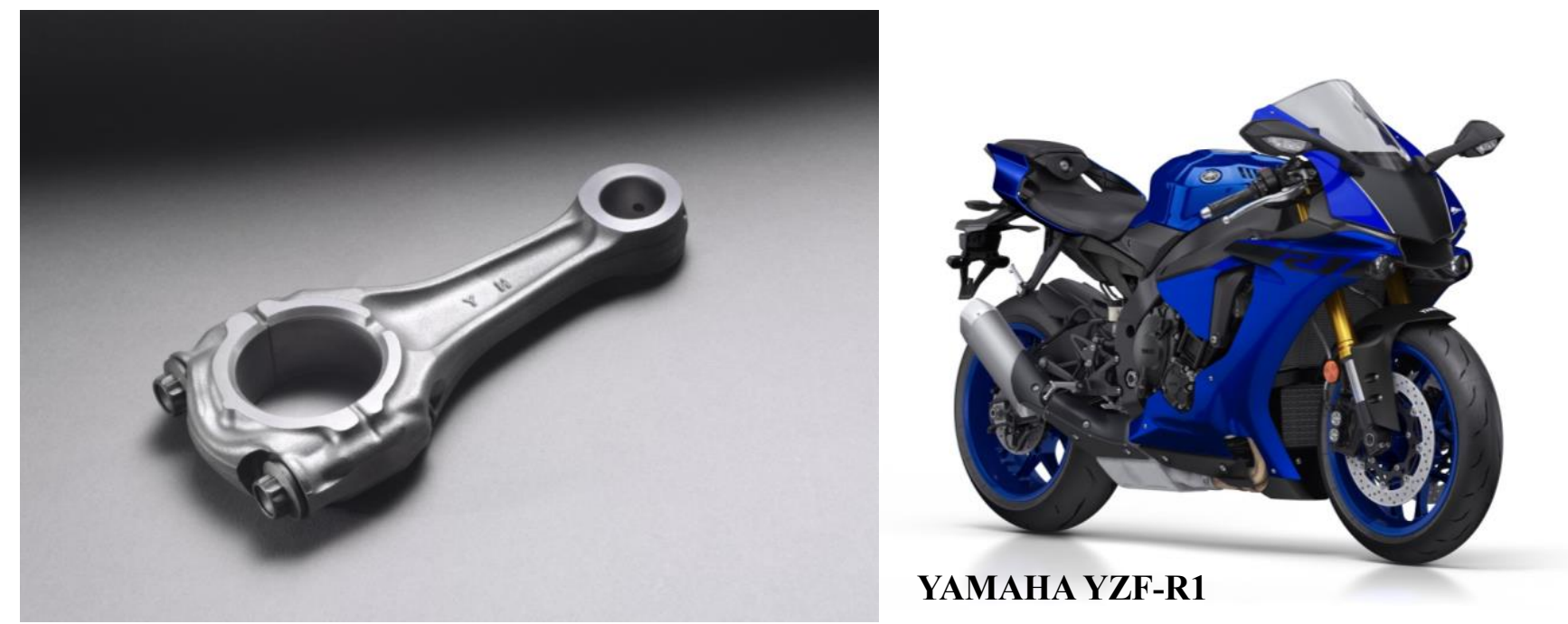

Figure 5. Appearance of the fracture-split connecting rod made of Ti-5Al-1Fe.

Courtesy of YAMAHA MOTOR Corporation、 YAMAHA YZF-R1

Engine valves

In drive system components such as engine valves and connecting rods, the reduction in their weight leads to an improvement of driving response and a decrease in the load on peripheral parts. In the latter, the effect of reduction of weight is strong since the weight of peripheral parts could also be reduced. Figure 6 shows tensile strength of Ti-5Al-2Fe-3Mo, Ti-6Al-4V and Ti-1100 as a function of temperature. For intake engine valves that are usually used at $300-400^{\circ} \mathrm{C}$, Ti-6Al-4V is generally applied. Recently, Ti-5Al-2Fe-3Mo with higher strength than Ti-6Al-4V has also been applied mainly to motorcycles [18], [19].

The strength of titanium alloys rapidly decreases at $500^{\circ} \mathrm{C}$ or higher and the materials that can be used for exhaust engine valves at approximately $700{ }^{\circ} \mathrm{C}$ are limited. Ti-1100 (Ti-6Al-2.75Sn-4Zr-0.4Mo-0.45Si) and Ti-6Al-2Sn-4Zr-2Mo-0.1Si (hereinafter Ti-6242S) that have high temperature strength as high as SUH35, heat-resistant-steel, at elevated temperatures over $500^{\circ} \mathrm{C}$, have been applied. Furthermore, creep strength is important for exhaust engine valves as well as high temperature fatigue strength and titanium alloys composed of acicular microstructure that show excellent creep resistance have been often used. In addition, Ti-5.8Al-4Sn-3.5Zr-2.8Mo-0.7Nb-0.35Si-0.06C, and the most recently developed Ti-7Al-2Mo-0.2Si-0.15C-0.2Nb,etc are applied as heat-resistant-titanium-alloys, which show equivalent heat resistance to those of Ti-6242S[20].

At the sliding portion of engine valves, $\mathrm{CrN}$ coating or oxidation heat treatment under air is applied as a treatment to improve wear resistance. However, $\mathrm{CrN}$ coating is expensive and oxidation heat treatment sometimes deteriorates the fatigue property due to the oxidized hardened layer. Therefore, in the case that the wear resistance is applied by oxidation heat treatment, deterioration of fatigue property is minimized by setting the appropriate oxidation conditions [18],[21]. There is a need for developing a low cost surface treatment technology by which both wear resistance and fatigue strength are obtained, as well as improving high temperature properties of titanium alloys, in order to apply them for severer conditions. 


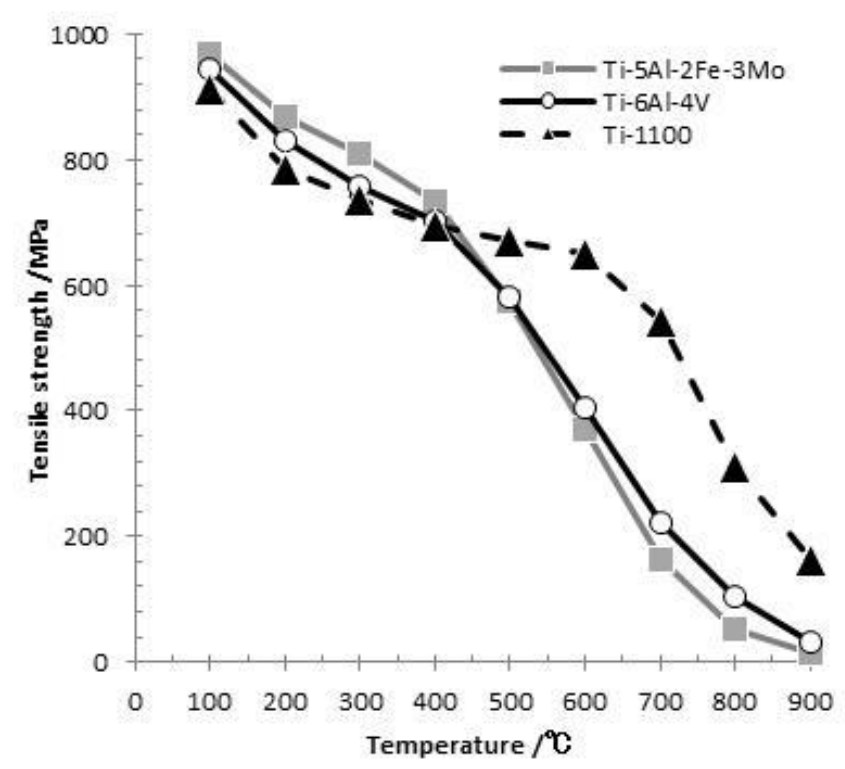

Figure 6. Tensile strength of Ti-5Al-2Fe-3Mo, Ti-6Al-4V and Ti-1100 as a function of temperature.

Hot rolled round bars were used (hot rolling reduction of $95 \%$ or more in $\alpha+\beta$ region).

Ti-5Al-2Fe-3Mo, Ti-6Al-4V were annealed at $750^{\circ} \mathrm{C}$ for $1 \mathrm{~h}$ followed by air cooling.

Ti-1100 was solution treated at $1100^{\circ} \mathrm{C}$ for 20 min and annealed at $750^{\circ} \mathrm{C}$ for $1 \mathrm{~h}$ followed by air cooling.

\section{Exhaust system}

In exhaust system parts, titanium has been adopted mainly for mufflers of motorcycles in view of design and weight reduction. However, since the exhaust gas temperature rose due to environmental measures, the heat resistance of the conventional ASTM Gr2 and JIS Class2 commercially pure titanium became insufficient. In addition to high temperature strength and oxidation resistance, press formability at room temperature has strongly been required since exhaust system parts are manufactured by press forming of sheets. Therefore, various heat-resistant titanium alloys, such as Ti-0.5Si-Fe (Ti-Exhaust XT), Ti-0.1Fe-0.35Si, Ti-1.5Al, Ti-0.5Al-0.45Si-0.2Nb (1.2 ASNEX), Ti-1Cu (10 CU), Ti-1 Cu-0.5 Nb (10 CUNB) and Ti-1 Cu-1 Sn-0.35 Si-0.2 Nb (10 CSSN) have been developed [13], [22]. The above-mentioned titanium alloys are roughly classified into Ti-Al-Si system and Ti-Cu system. The addition of $\mathrm{Al}, \mathrm{Si}, \mathrm{Sn}$ and $\mathrm{Cu}$ causes to improve the high temperature strength. Furthermore, $\mathrm{Nb}$ and $\mathrm{Si}$ are added to ensure oxidation resistance and salt damage corrosion resistance at elevated temperatures [18], [23], [24], [25]. The unique character in the case that $\mathrm{Cu}$ is added is that the solid solution strengthening ability of $\mathrm{Cu}$ at high temperature is very large, while the suppression of twin deformation which promotes plastic deformation at room temperature is relatively small [18],[26],[27]. Examples of applications of these titanium alloys to commercial four-wheeled vehicles are: Ti-1Cu for NISSAN GTR spec-V in 2009 and for NISSAN GT-R in 2016 and Ti-0.5Al-0.45Si-0.2Nb for TOYOTA LEXUS LFA in 2009.

\section{Fuel cell separator}

Separators made of commercially pure titanium foils have been adopted in the fuel-cell vehicle "MIRAI" of Toyota Motor Corporation in 2014. MIRAI is equipped with Polymer electrolyte fuel cells, PEFCs. PEFCs have a high output density although they are operated at low temperatures of $70-90^{\circ} \mathrm{C}$. Therefore, they are mainly used in FCVs and they need to be made lighter and smaller [28],[29],[30],[31]. In PEFCs, hydrogen and oxygen are used as the reactant gases 
and hydrogen ions which are selectively permeated to organic membranes are used as the electrolyte. Their operating temperature is lower than $100^{\circ} \mathrm{C}$. As shown in Figure 7, separators are pressed onto both sides of the membrane electrode assembly (MEA) in which a solid polymer membrane, electrodes, and gas diffusion layers are combined, a large number of which are laminated to form a stack. The properties that are required for separators are electrical conductivity, separation of oxygen gas and hydrogen gas at both electrodes, low contact resistance with the carbon paper constituting the MEA's gas diffusion layers, and excellent durability under the corrosive sulfuric acid environment in fuel cells[28],[29],[30],[31],[32].

In addition to graphite type separators, metal separators using corrosion-resistant metals (e.g., titanium and stainless steel) have also been developed since titanium and stainless steel are cold workable (e.g. cold rolled and press formed) and it is not difficult to produce their foil products. Passive films (oxide films) naturally formed on the surfaces of these corrosion-resistant metals exhibit high corrosion resistance. However, their electrical resistance is high and the contact resistance with carbon paper becomes higher. Therefore, several technologies for titanium have been being studied, including coating the surfaces with $\mathrm{Au}$ or other precious metals, or conductive resin[30],[33],[34] and applying titanium alloys added with trace quantities of precious metal elements (e.g., Pd, Pt, and $\mathrm{Au}$ ) that concentrate at the surfaces through pickling[29] to realize high corrosion resistance and low contact resistance at the same time.

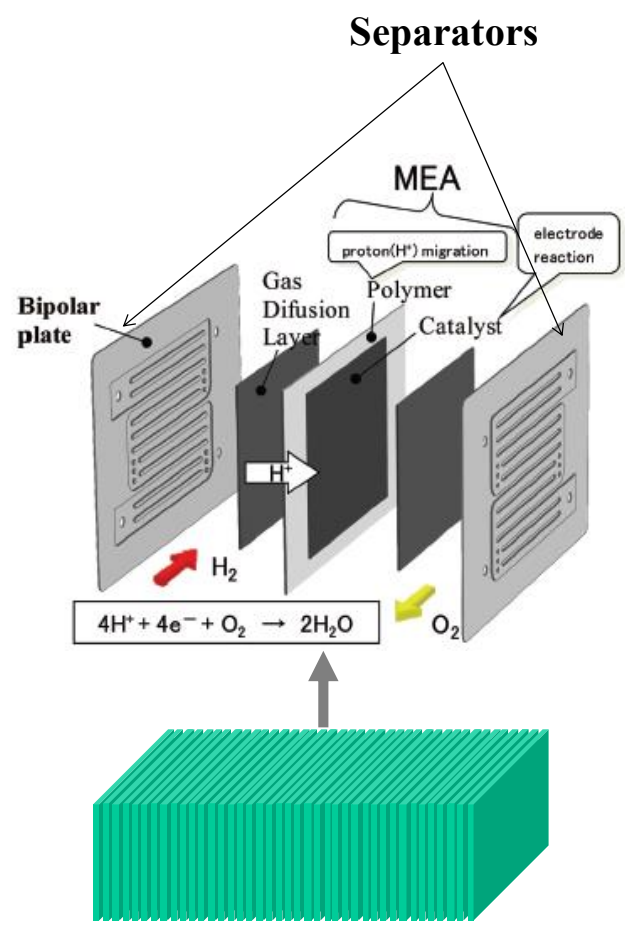

Fuel Cell stack

Figure 7. Schematic image of structure of PEFC

\section{Summary}

Several examples of application of titanium and its alloys for automobile parts are introduced. In recent years, titanium and its alloys have newly been adopted to fracture-split connecting rods, fuel tanks, and fuel cell separators of mass produced vehicles because of not only the development of titanium alloys in which low-cost alloying elements are added 
and low-cost processing are carried out by material producers, but also the cooperative development by material producers, parts makers and car manufactures. Titanium has potentially superior material properties and may play an important role as the situation changes, for example, in the case that the number of EV increases. In order to expand the application of titanium, the joint promotion and the cooperative development is considered to be important in the future.

\section{References}

[1] T.Nakazawa and M.Iharagi.: JFA, Journal of the Japan Forging Association, 45 (2014)17-27.

[2] T.Suzuki: Journal of the Japan Light Welding Association, 53(2015)77-82.

[3] T.Suzuki, T.Kubota, T.Kitsunai, M.Asano and K.Takahashi,: Journal of the Japan Institute of Light Metals, $67,2(2017) 50-56$

[4] A.Fujita, T.Nakashima, S.Ikehata and S.Okano: Knowledge creation and integration, edited and published by Nomura Research Institute, 4 (2017)46-63.

[5] K. Hirano and Y. Chihara: JSAE2018512, Proceedings of 2018 Annual Congress (Spring), Jpn, No.28-18(2017)

[6] H.Fukutomi: Fuel car lightweighting material-from development to application-, CMC Publishing Co.,Ltd., Tokyo, Jpn., (2006)197.

[7] T.Yasunaga, A.Hirano, S.Yano, Y.Tomaru,Y.Sagawa, T.Watanabe, and H.Fujiwara: Yamaha Motor Tech. Rev., (2015)35-42.

[8] A.Kawakami: Bull. Iron Steel Inst. Jpn.23(2018)580-584.

[9] T.Kubota and K.Takahashi: Bull. Iron Steel Inst. Jpn.23(2018)585-590.

[10] K.Takahashi and Y.Marui: Titanium Jpn.,50 (2002)93-97.

[11] E.Sato and K.Takahashi: Ti-2007 Science and Technology, edited by M.Niinomi, S.Akiyama, M.Hagiwara, K.Maruyama,the Jpn. Institute of Metals, (2007)1379-1382.

[12] T.Matsubara, Y.Sato, K.Kimura, N.Kawase and S.Ito: HONDA R\&D Technical Review, 3(1991)12-26.

[13] L.Wagner and O.Schauerte: Ti-2007 Science and Technology, edited by M.Niinomi, S.Akiyama, M.Hagiwara, K.Maruyama,the Jpn. Institute of Metals, (2007)1371-1378.

[14] H.Fujii, K.Takahashi, S.Soeda and M.Hanaku: Titanium '95, edited by P.A.Blenkinsop, W.J.Evans and H.M.Flower,TIM(1996)2539-2546.

[15] H.Fujii and K.Takahashi: Nippon Steel Tech. Rep., 375(2001)99-103.

[16] H.Fujii: Titanium Jpn.,64 (2016)125-129.

[17] H.Fujii and T.Maeda: Nippon Steel \& Sumitomo Metal Tech. Rep.,396(2013)16-22.

[18] K.Mori: Titanium Jpn.,67(2019)88-92.

[19] K.Mori, K.Takahashi and H.Fujii: Titanium Jpn., 55(2007)1-5.

[20] S.Kasatori,Y.Marui, K.Ono and H.Oyama: JSAE20175087, Proceedings of 2017 Annual Congress (Spring), Jpn, No.20175087(2017)466-471.

[21] H.Fujii, K.Takahashi and Y.Yamashita: Nippon Steel Tech. Rep.,378(2003)63-67.

[22] Y.Kosaka, S.P.Fox and K.Faller: Ti-2007 Science and Technology, edited by M.Niinomi, S.Akiyama, M.Hagiwara, K.Maruyama, the Jpn. Institute of Metals, (2007)1383-1386.

[23] T.Yashiki and K.Yamamoto: Titanium Jpn.,54(2006)120-129. 
[24] T.Yashki: Ti-2007 Science and Technology, edited by M.Niinomi, S.Akiyama, M.Hagiwara, K.Maruyama, the Jpn. Institute of Metals, (2007)1387-1390.

[25] K.Mori, K.Takahashi, H.Fujii and H.Otsuka: CAMP-ISIJ, 28(2015)389.

[26] H.Otsuka, H.Fujii, K.Takahashi and M.Ishii: Ti-2007 Science and Technology, edited by M.Niinomi, S.Akiyama, M.Hagiwara, K.Maruyama, the Jpn. Institute of Metals, (2007)1391-1394.

[27] H.Otsuka, H.Fujii, K.Takahashi,M.Masaki and M.Sato: Materia Japan, 49 (2010)75-77.

[28] Y.Tarutani, A.Seki, T.Doi, Y.Masaki and T.Kudo: Proceedings of Solid Polymer Electrolyte Fuel Cell/Hydrogen Energy Utilization Achievement Report Meeting, New Energy and Industrial Technology Development Organization, Kanagawa, (2003)79-82.

[29] T.Satoh, S.Sakashita, T.Yashiki and M.Fukuda: Kobe Steel Eng. Rep., 55 (2005)48-51.

[30] T.Satoh and J.Suzuki: Kobe Steel Eng. Rep., 60(2010)29-32.

[31] J.Imamura and Y.Tarutani: Nippon Steel \& Sumitomo Metal Tech. Rep., 396(2013), 111(in Japanese); 106(2014), $108-113$.

[32] M.Ueda, Y.Mori, M.Hashimoto, S.Yamamuro, S.Tanase, Y.Aoi, Y.Iwasa and S.Sakai: J. Japan Inst. Metals, 71(2007), 545-552.

[33] M.Seido and O.Yoshioka: Titan. Jpn., 52(2004), 291-295.

[34] M.Washima, M.Seido, K.Nakagawa, H.Numata: Hitachi Cable Tech. Rep., 24-1(2005), 39-42. 